\title{
Evaluation of pedicled flaps for type IIIB open fractures of the tibia at a tertiary care center
}

\author{
Madhubari Vathulya ${ }^{1}$, Mohit Dhingra ${ }^{2}$, Hawaibam Nongdamba ${ }^{2}$, Debarati Chattopadhyay ${ }^{1}$, \\ Akshay Kapoor ${ }^{1}$, Vandana Kumar Dhingra ${ }^{3}$, Vishal Mago ${ }^{1}$, Pankaj Kandwal ${ }^{2}$ \\ Departments of ${ }^{1}$ Plastic Surgery, ${ }^{2}$ Orthopedics, and ${ }^{3}$ Nuclear Medicine, All India Institute of Medical Sciences, Rishikesh, India
}

Background Soft tissue coverage plays a vital role in replacing the vascularity of the underlying bone in Gustilo type IIIB fractures. The aim of this article was to evaluate the feasibility of local pedicled flaps in type IIIB fractures at a tertiary care center.

Methods We included all cases of open Gustilo-Anderson type IIIB fractures of the tibia treated with local flap coverage from January 2017 to February 2019. We carried out a retrospective analysis to investigate the relationships of complications, hospital stay, and cost-effectiveness with the choice of flap, infective foci, site and size of the defect, and type of fixation.

Results Out of 138 Gustilo type IIIB fractures analyzed in our study, 27 cases had complications, of which $19(13.76 \%)$ involved flap necrosis, four (2.89\%) were infections, three (2.17\%) involved partial necrosis, and one $(0.72 \%)$ was related to bone spur development. Flap complications showed a statistically significant association with the perforator flap category (propeller flaps in particular) $(\mathrm{P}=0.001)$. Flap necrosis showed a significant positive correlation with cases treated within 3 weeks after trauma $(P=0.046)$. A significant positive correlation was also found between defect size and the duration of hospital stay $(P=0.03)$.

Conclusions Although local flaps are harvested from the same leg that underwent trauma, their success rate is at least as high as microvascular flaps as reported from other centers. Amidst the local flaps, complications were predominantly associated with perforator flaps.

Keywords Limb salvage / Lower extremity / Open fractures / Reconstructive surgical procedure / Surgical flaps

Received: October 22, 2020 • Revised: May 7, $2021 \bullet$ Accepted: May 27, 2021

pISSN: 2234-6163 • elSSN: 2234-6171 • https://doi.org/10.5999/aps.2020.02089• Arch Plast Surg 2021;48:417-426
Correspondence: Mohit Dhingra Department of Orthopedics, All India Institute of Medical Sciences, 504 Peer Wali Gali, Arya Nagar, Jwalapur, Rishikesh 248201, India Tel: +91-135-2462976 Fax: +91-135-2462941 E-mail:modisbanu77@gmail.com

\section{INTRODUCTION}

The recent technological advances experienced by humanity are not without disadvantages, including an increased frequency of high-velocity trauma and industrial accidents, resulting in an increased incidence of open fractures.

Open fractures pose a challenge to the trauma team in terms of loss of soft tissue, loss of bone, the presence of contamination potentially leading to infection, and an elevated incidence of non-union. In view of these anticipated complications, the need for aggressive debridement, adequate fracture fixation, and early flap coverage in reducing morbidity cannot be overemphasized [1]. Achieving those goals is only possible when there is a collective approach involving all trauma team members, including the plastic surgeon and orthopedic surgeon, aiming to save the limb.

For the soft-tissue coverage of defects, either microvascular- 
free flaps or non-microvascular local flaps are available. There is no clear dictum regarding the choice of flap [2], although nonmicrovascular local flaps are comparatively easier to perform given the lower requirements in terms of infrastructure and expertise [3].

The main concern regarding local flaps is that reconstructive surgeons are generally sceptical about the survival of local flaps harvested from a traumatic zone [4]. This underscores the need for empirical research to establish the actual feasibility of these flaps in a trauma scenario by analyzing flap complications and assessing the impact of these complications on cost-effectiveness for both the patient and the treating hospital.

\section{METHODS}

The study was conducted at the department of orthopedics and plastic surgery at a tertiary care hospital. All cases of open Gustilo-Anderson type IIIB fractures of the tibia that received soft tissue coverage in the form of non-microvascular flaps from January 2017 to February 2019 were included. Written informed consent of the patients was obtained at the time of surgery, when they received an explanation of the type of procedure they would undergo. Cases operated at other centers, primarily for debridement and bony fixation, that were referred to us for soft tissue coverage were also included. A retrospective analysis of these cases was conducted, considering the following factors: (1) time of presentation: acute or chronic (less than 3 weeks or more than 3 weeks after injury); (2) status of the exposed bone cortex: with or without periosteum; (3) soft-tissue defect dimensions ( $<5 \mathrm{~cm}, 5-10 \mathrm{~cm}, 10-15 \mathrm{~cm}, 15-20 \mathrm{~cm}$, and $>20$ $\mathrm{cm})$; (4) site of the defect (proximal, middle, or distal third); (5) the area involved (anteromedial, anterolateral, posterolateral, posteromedial, or a combination thereof); (6) type of flap coverage; or (7) complications (partial necrosis, complete necrosis, incidence of infection, and any other complication).

These cases were then tabulated and analyzed using the Pearson chi-square test in SPSS version 23 (IBM Corp., Armonk, NY, USA).

\section{RESULTS}

\section{Preoperative analysis}

Of the 138 patients who were included in the study, 115 (83.3\%) were male and 23 were female (16.7\%). Among them, 39 cases presented within 3 weeks after the injury (acute), while the remaining 99 cases presented more than 3 weeks after the injury (chronic).

The age of the patients ranged from 4 to 60 years, with an aver- age of 34.4 years. The distal third of the leg was most commonly involved ( 46 cases), followed by the middle third ( 40 cases) and proximal third (39 cases).

According to the site of involvement, the most commonly affected area was distal (anteromedial distal, 14.5\%; posteromedial distal, $7.5 \%$ ), followed in descending order by the proximal zone (anteromedial proximal, 13.8\%; posteromedial proximal, $7.5 \%$ ) and the middle zone (anteromedial middle, 11.6\%) (Fig. 1 ). In addition, In the proximal and middle zones, the posterolateral aspect was least commonly involved.

The size of the soft tissue defects was distributed as follows: $5-10 \mathrm{~cm}$ (10.9\%), 10-15 cm (16.7\%), 15-20 cm (32.6\%), and $>20 \mathrm{~cm}$ (39.9\%).

Age, sex, the site of the defect, the size of the defect, and the chronicity of the wound did not have any significant correlations with complications.

\section{Postoperative and intraoperative analysis}

Ninety-seven patients (70.3\%) underwent external fixation, while 41 patients $(29.7 \%)$ underwent internal fixation, including plating and intramedullary nailing. In the 97 cases of external fixation, complications were seen in 19 cases (19.5\%), while in the 41 cases of internal fixation, eight (19.5) had complications. The association between complications and type of fixation was not found to be statistically significant $(\mathrm{P}=0.7)$.

Out of the total number of cases, 104 (75.36\%) underwent fasciocutaneous flaps and 34 (24.64\%) underwent muscle or musculocutaneous flaps. Among the fasciocutaneous flaps, perforator flaps (including propeller flaps) were the most predominant variety used $(27 / 104,25.96 \%)$, and gastrocnemius muscle or musculocutaneous flaps were predominant $(31 / 34,94.11 \%)$ in the muscle flap category (Fig. 2).

Among the 104 cases of fasciocutaneous flaps (Fig. 3), 86 cases $(82.7 \%)$ had no complications and 18 cases $(17.3 \%)$ had complications. Among the 34 cases of musculocutaneous flaps, 25 cases $(73.5 \%)$ had no complications and nine cases (26.5\%) had complications. Although the difference did not reach statistical significance, musculocutaneous flaps showed a higher percentage of complications (26.5\%). However, in a comparison of complications among the different flap groups, a higher percentage of flap necrosis was seen in perforator flaps (including propeller flaps) (Figs. 4, 5) accounting for $21.1 \%$ of cases, followed by two cases each for the five other types of flaps. This association was statistically significant $(\mathrm{P}=0.001)$ (Table 1$)$.

Of the 138 cases, 38 had a hospital stay lasting for < 3 weeks, while 100 had a hospital stay $>3$ weeks. In our study, the average duration of the hospital stay for acute and chronic cases was $28.05 \pm 13.00$ days and $36.37 \pm 16.64$ days, respectively. We 

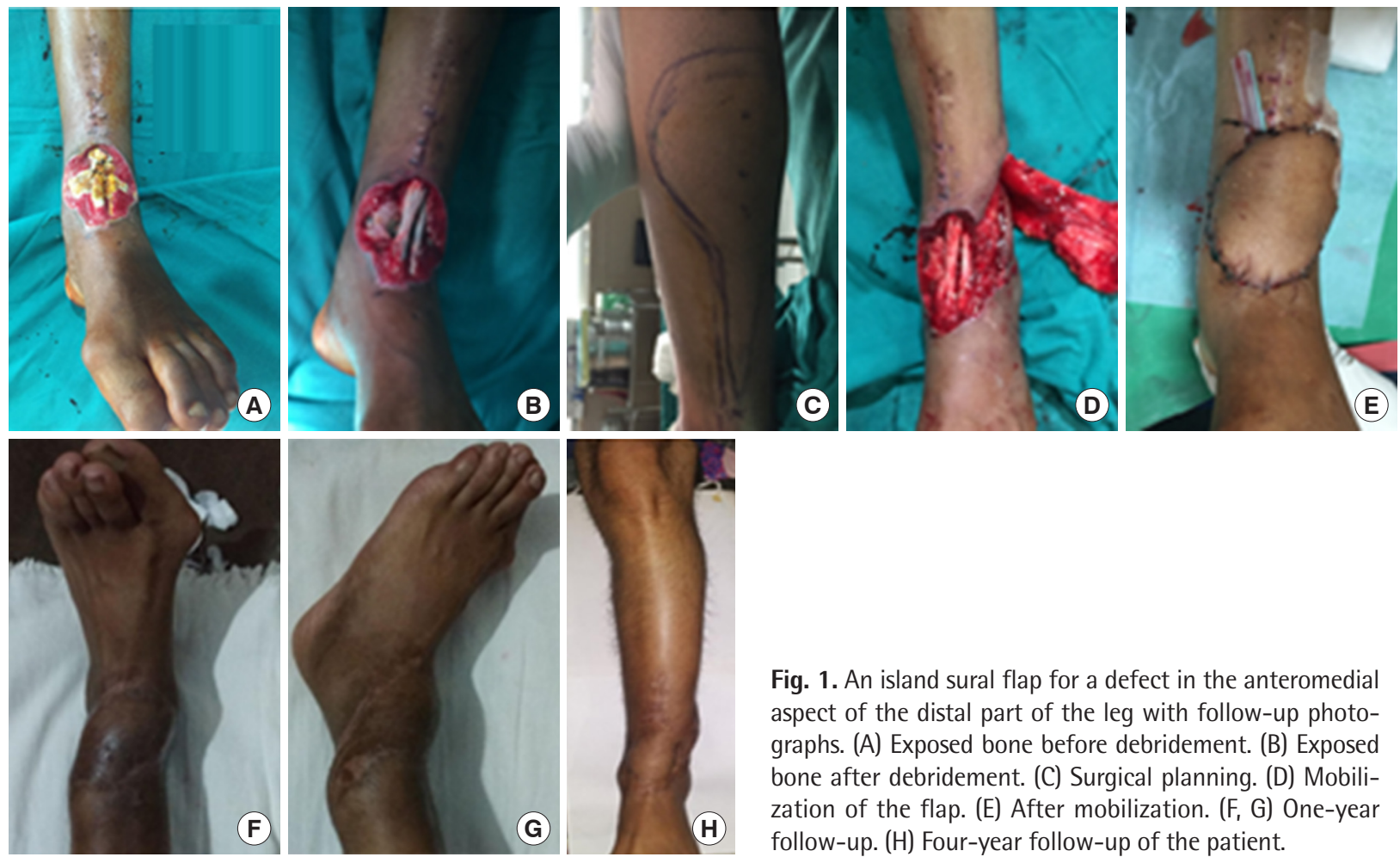

Fig. 1. An island sural flap for a defect in the anteromedial aspect of the distal part of the leg with follow-up photographs. (A) Exposed bone before debridement. (B) Exposed bone after debridement. (C) Surgical planning. (D) Mobilization of the flap. (E) After mobilization. $(F, G)$ One-year follow-up. (H) Four-year follow-up of the patient.
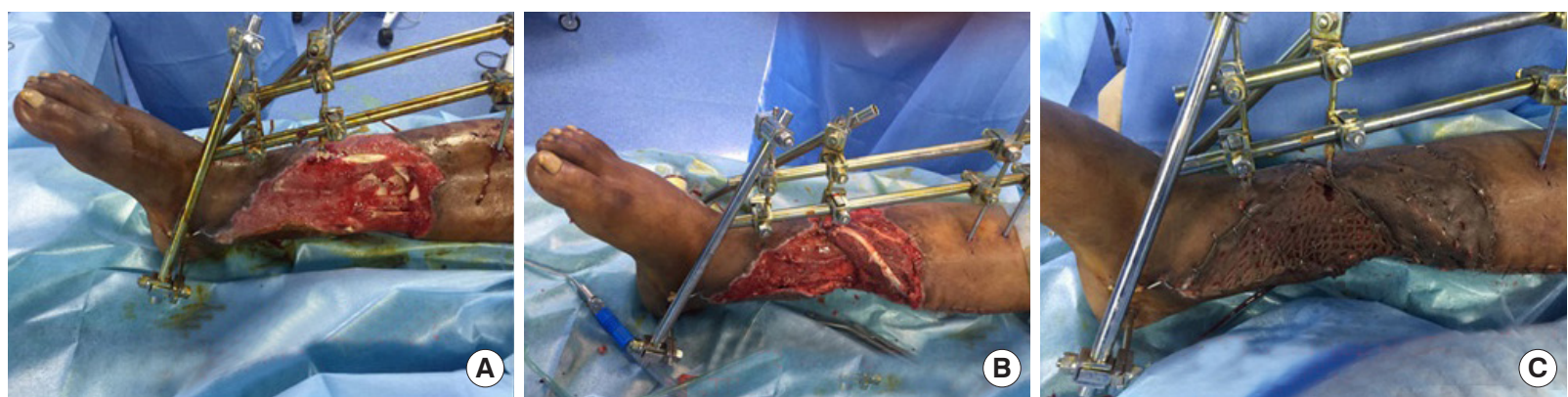

Fig. 2. A soleus flap for a defect in the distal part of the tibia. (A) Wound prepared for flap cover. (B) Soleus rerouted cover the exposed bone. (C) Raw surface left covered with a skin graft.
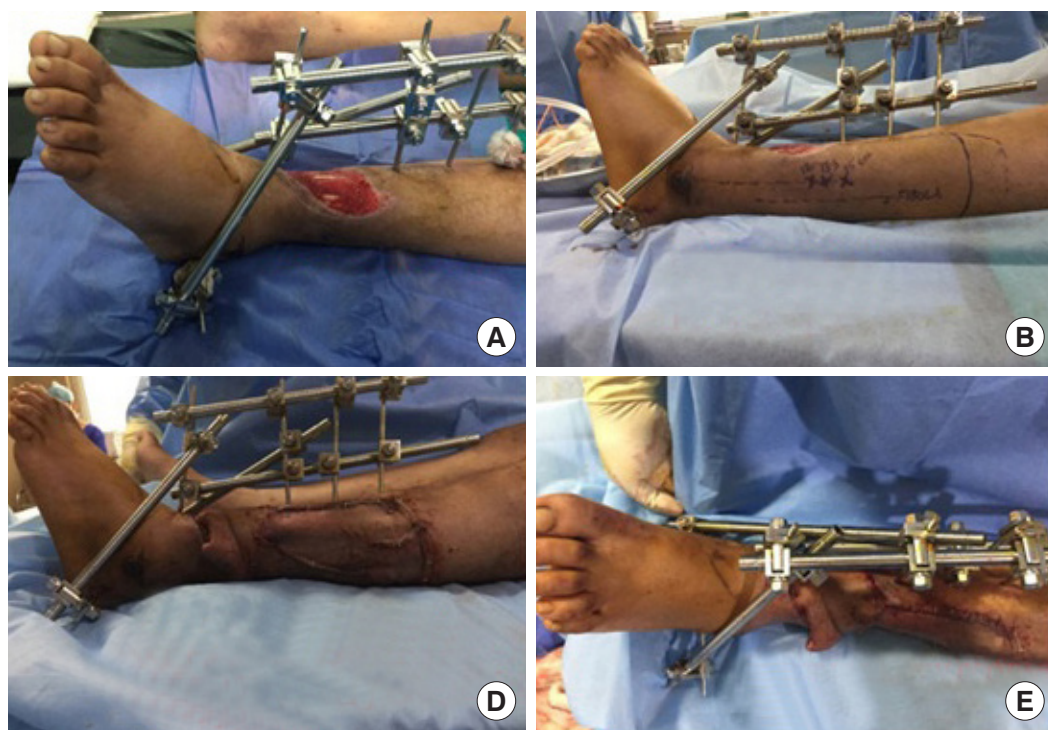

(B)

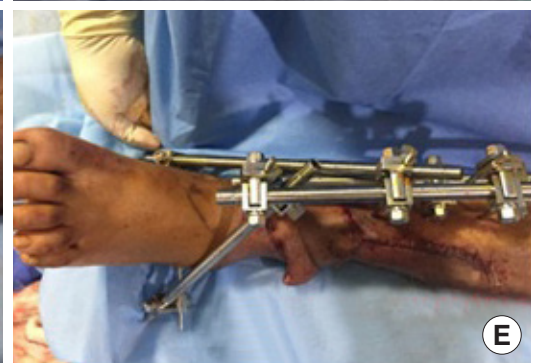

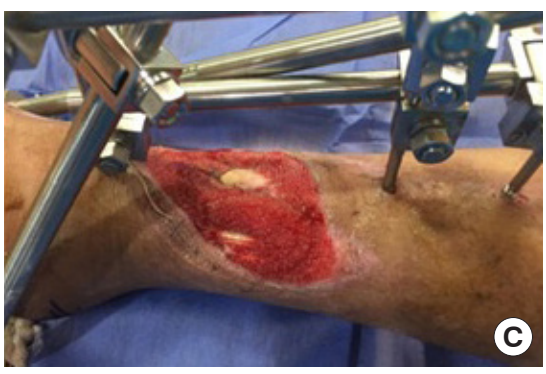

Fig. 3. The inferior peroneal artery fascia flap was performed for the distal tibia. (A) Primitive wound. (B) Surgical plan. (C) Close-up of view of raw wound. (D, E) Lateral and superior views of the inferiorbased peroneal artery fascia flap. 

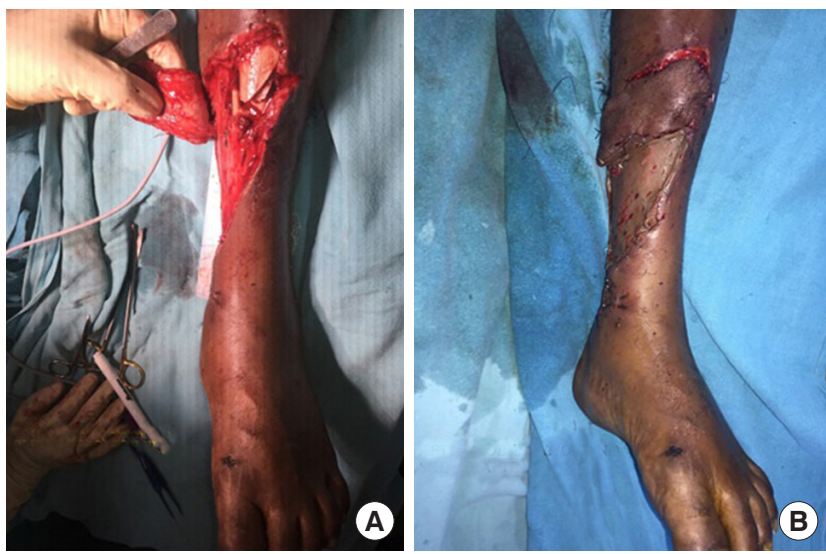

Fig. 4. A perforator flap for a defect in the distal tibia. (A) Mobilization of the flap. (B) After mobilization and skin grafting.

found that the proportion of cases with a hospital stay lasting for $>3$ weeks steadily increased-from $6 \%$ to $18 \%, 34 \%$, and $42 \%$ - as the size of the soft tissue defects increased from 5-10 $\mathrm{cm}$ to $10-15 \mathrm{~cm}, 15-20 \mathrm{~cm}$, and $>20 \mathrm{~cm}$, respectively, and this relationship was statistically significant $(\mathrm{P}=0.030)$ (Table 2 ). However, there was no statistically significant correlation between the soft tissue defect size and complications $(\mathrm{P}=0.572)$, or between the choice of flap and the duration of hospital stay $(\mathrm{P}=0.390)$.

\section{Statistical analysis}

Correlational analysis using the Pearson chi-square test was performed between the types of flaps, bony fixation, the size of the defect, the site of the defect, age group, and sex and complications to identify factors related to complications. Correlations were also calculated between flap type, defect size, and the length of hospital stay to determine factors influencing the duration of inpatient care.

A significant correlation was found between the type of flap and the complication rate. Perforator flaps had the highest frequency of flap necrosis $(21.1 \%)$, with a P-value of 0.001 for the correlation. Meanwhile, age, sex, the site of the defect, the size of the defect, the type of bony fixation, and the chronicity of the wound did not have any significant correlations with complications. Complications were also more common in patients who underwent surgery during the acute period (less than 3 weeks following trauma) than in those who underwent surgery later.

\section{DISCUSSION}

Lower limb trauma is a rapidly-growing category of injuries worldwide as a result of road traffic and industrial accidents. Reconstructive surgeons are normally involved in lower limb trau-
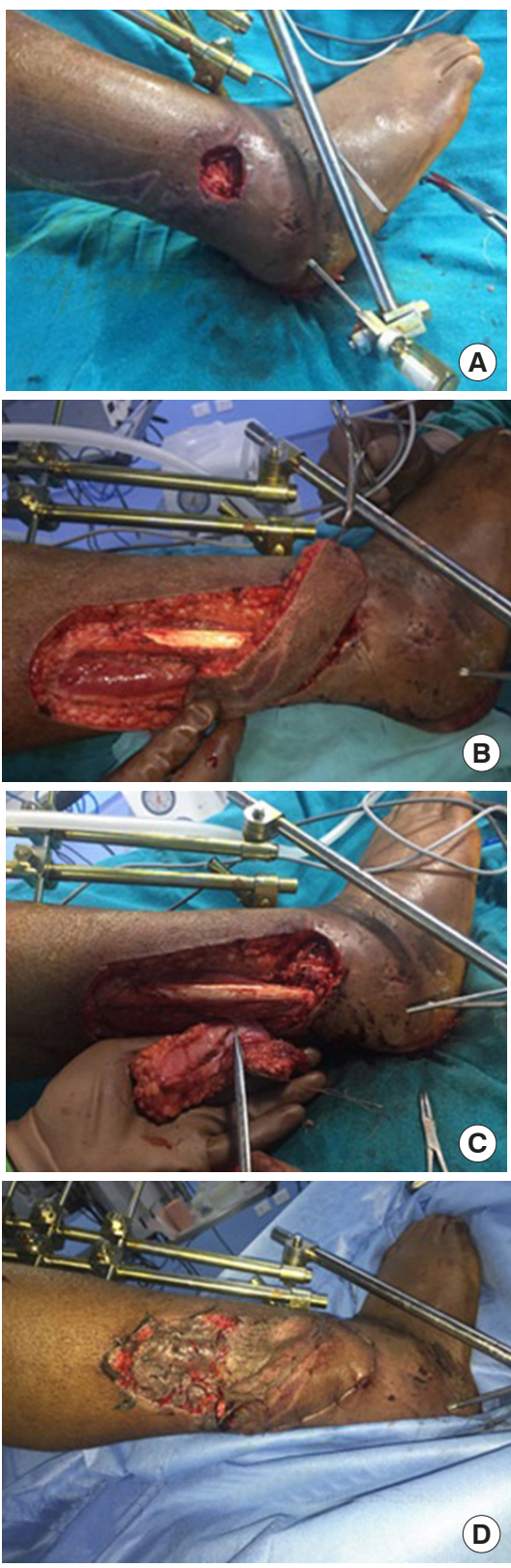

Fig. 5. A propeller flap for a defect in the lateral aspect of the distal leg. (A) Soft tissue defect. (B) Mobilization of the flap. (C) Surgical dissection and mobilization. (D) Coverage of the exposed none and skin grafting.

ma management of Gustilo type IIIB and IIIC injuries. Soft tissue defects are predominantly dealt with using pedicled or free flaps, and the outcomes are variable. The benefits of flap reconstruction in fractures have already been established in several studies [1]. Numerous researchers have tried to identify factors that determine the flap outcomes in fracture patients.

It is imperative that trauma centers that handle these cases make attempts to evaluate the outcome of reconstructions. Doing so will enable the team and the center to improve their decision-making and to make better predictions regarding their pa- 
Table 1. Correlations between flap types and complications

\begin{tabular}{|c|c|c|c|c|c|c|c|c|c|}
\hline \multirow[b]{2}{*}{ Flap types and complications } & \multicolumn{6}{|c|}{ Complications } & \multicolumn{3}{|c|}{ Chi-square } \\
\hline & None & $\begin{array}{l}\text { Bone } \\
\text { spur }\end{array}$ & $\begin{array}{c}\text { Flap } \\
\text { necrosis }\end{array}$ & Infection & $\begin{array}{c}\text { Partial } \\
\text { necrosis }\end{array}$ & Total & Value & df & P-value \\
\hline Superiorly-based posterior tibial fasciocutaneous flaps & $12(10.8)$ & 0 & $1(5.3)$ & 0 & 0 & $13(9.4)$ & 156.35 & 64 & $<0.001^{a)}$ \\
\hline Inferiorly-based peroneal artery fasciocutaneous flap & $1(0.9)$ & 0 & 0 & 0 & 0 & $1(0.7)$ & & & \\
\hline $\begin{array}{l}\text { Gastrocnemius musculocutaneous flaps for medial defects and } \\
\text { superiorly-based peroneal artery fasciocutaneous flaps (combined) }\end{array}$ & $1(0.9)$ & 0 & $2(10.5)$ & $1(25.0)$ & 0 & $4(2.9)$ & & & \\
\hline Sural flaps & $9(8.1)$ & 0 & $2(10.5)$ & $1(25.0)$ & 0 & $12(8.7)$ & & & \\
\hline Inferiorly-based posterior tibial fasciocutaneous flaps & $4(3.6)$ & 0 & 0 & 0 & 0 & $4(2.9)$ & & & \\
\hline Superiorly-based peroneal artery fasciocutaneous flaps & $9(8.1)$ & 0 & $2(10.5)$ & $1(25.0)$ & 0 & $12(8.7)$ & & & \\
\hline Gastrocnemius muscle flaps & $18(16.2)$ & 0 & $2(10.5)$ & 0 & $1(33.3)$ & $21(15.2)$ & & & \\
\hline Medial gastrocnemius musculocutaneous flaps & $1(0.9)$ & 0 & 0 & 0 & 0 & $1(0.7)$ & & & \\
\hline Perforator or propeller flaps & $20(18.0)$ & 0 & $4(21.1)$ & 0 & $1(33.3)$ & $25(18.1)$ & & & \\
\hline Inferiorly-based inferior genicular artery fasciocutaneous flaps & $4(3.6)$ & 0 & 0 & 0 & 0 & $4(2.9)$ & & & \\
\hline Cross leg flaps & $13(11.7)$ & 0 & $2(10.5)$ & 0 & 0 & $15(10.9)$ & & & \\
\hline Inferiorly-based peroneal artery fasciocutaneous flaps & $8(7.2)$ & 0 & $1(5.3)$ & 0 & 0 & $9(6.5)$ & & & \\
\hline Keystone flaps & $5(4.5)$ & 0 & $1(5.3)$ & 0 & 0 & $6(4.3)$ & & & \\
\hline Posterior tibial artery-based propeller flaps & $1(0.9)$ & 0 & $1(5.3)$ & 0 & 0 & $2(1.4)$ & & & \\
\hline Soleus muscle flaps & 0 & $1(100)$ & 0 & $1(25.0)$ & 0 & $2(1.4)$ & & & \\
\hline Musculocutaneous flaps & $5(4.5)$ & 0 & $1(5.3)$ & 0 & 0 & $6(4.3)$ & & & \\
\hline Superiorly-based anterior tibial artery fasciocutaneous flaps & 0 & 0 & 0 & 0 & $1(33.3)$ & $1(0.7)$ & & & \\
\hline Total & $111(100)$ & $1(100)$ & $19(100)$ & $4(100)$ & $3(100)$ & $138(100)$ & & & \\
\hline
\end{tabular}

Values are presented as number (\%).

a) Statistically significant, $\mathrm{P}<0.05$.

Table 2. Correlation between the size of soft tissue defects and the duration of hospital stay

\begin{tabular}{|c|c|c|c|c|c|c|}
\hline & \multicolumn{3}{|c|}{ Crosstab, №. (\%) } & \multicolumn{3}{|c|}{ Chi-square } \\
\hline & \multicolumn{2}{|c|}{ Hospital stay } & \multirow{2}{*}{ Total } & \multirow{2}{*}{ Value } & \multirow{2}{*}{ df } & \multirow{2}{*}{ P-value } \\
\hline & $\leq 3$ Weeks & $>3$ Weeks & & & & \\
\hline $\begin{array}{l}\text { Soft tissue defect } \\
\text { size }(\mathrm{cm})\end{array}$ & & & & 8.945 & 3 & $0.030^{\mathrm{a})}$ \\
\hline $5-10$ & $9(23.7)$ & $6(6.0)$ & 15 (10.9) & & & \\
\hline $10-15$ & $5(13.2)$ & $18(18.0)$ & $23(16.7)$ & & & \\
\hline $15-20$ & $11(28.9)$ & $34(34.0)$ & 45 (32.6) & & & \\
\hline$>20$ & $13(34.2)$ & $42(42.0)$ & 55 (39.9) & & & \\
\hline Total & $38(100)$ & 100 (100) & $138(100)$ & & & \\
\hline
\end{tabular}

a) Statistically significant, $\mathrm{P}<0.05$.

tients' prognoses. It will also help establish a cost-effective model both for the center and for patients. A similar study was conducted at our institution to investigate the factors determining flap complications and the length of hospital stay in these patients. A retrospective study was designed, the data were compiled using patients' case files, and the results were analyzed. As an initial step, we sought to analyze the existing predisposing factors of flap complications and length of hospital stay.

\section{Factors contributing to flap failure}

Prior studies in the literature have identified several factors, including chronicity of presentation, age, comorbidities (e.g., diabetes) hindering wound healing, diabetes, type of fixation, and defect size, as associated with flap failure.

These studies have provided valuable insights into the predictive factors of flap failure; hence, the above-mentioned factors were incorporated in our study.

\section{Age and flap complications}

The majority of the cases in our study were in the age group of 21-40 years, which accounted for $54.3 \%$ of cases, followed by the age groups of $40-60$ years, $<20$ years, and $>60$ years, which accounted for $30.4 \%, 12.3 \%$, and $2.9 \%$ of cases, respectively. No statistically significant correlation was found between age groups and flap complications $(\mathrm{P}=0.523)$. However, the proportion of complications increased with age. Our finding is comparable with the findings of the study conducted by Ivanov et al. [5], in which the majority of the cases were in the age range of 31-45 years (35\%), followed by the age groups of 18 $30,46-60$, and $>60$ years, which accounted for $34 \%, 20 \%$, and $7 \%$ of cases, respectively. However, a systematic review by de Blacam et al. [2] correlated sural flap complications with predisposing factors and reported that age and venous insufficiency were independent risk factors for flap and wound complications. The study by Innocenti et al. [6] implicated age, flap dimensions, arc of rotation, peripheral vascular disease, and comorbidities such as diabetes as chief factors causing complications in perforator flaps. The study by Lese took into account the Charlson comorbidity index, which considers various co- 
morbidities, and the vascular axis on which the propeller flaps were based $[7,8]$. They concluded that the use of peroneal artery-based propeller flaps and a Charlson comorbidity index of 2 or greater were definite risk factors.

\section{Sex and flap complications}

In our study, 23 cases (16.7\%) were female and 115 (83.3\%) were male. Three of the 23 female patients (13\%) had complications in the form of flap necrosis, while 14 of the 115 male patients (12.2\%) had various complications. No statistically significant correlation was found between sex and complications. In the study by Ivanov et al. [5], 15 cases $(17.6 \%)$ were female and $70(82.4 \%)$ cases were male, which is a comparable ratio to that of our study. In the study conducted by Chua et al. [9], 6.74\% of the patients were female patients and $93.36 \%$ were male. Neither of those studies compared complications according to sex.

\section{Early and late presentation}

We observed that out of 138 cases, 39 had an acute presentation (<3 weeks) and 99 had a chronic presentation (>3 weeks) (Table 3). Among the 39 cases with an acute presentation, 30 (76.90\%) had no complications, while nine $(23.10 \%)$ had complications in the form of flap necrosis. Among the 99 cases with a chronic presentation, 81 (81.80\%) had no complications and 18 (18.20\%) had complications. Flap necrosis was significantly more common in the acute cases $(23.1 \%)$ than in the chronic cases $(10.1 \%)$, and this difference was statistically significant $(\mathrm{P}<0.05)$. In a study conducted by Kamath et al. [10] that analyzed 151 cases, patients who presented within 10 days, from 10 days to 6 weeks, and at $>6$ weeks had complication rates of $26.6 \%, 73.68 \%$, and $52.6 \%$, respectively [10]. In another study by Chua et al. [9], among 30 early flap coverage cases $(<72$ hours), 15 cases (54\%) had no complications and 14 cases (46\%) had complications, while among 59 late flap coverage cases ( $>72$ hours), 42 had complications. That study suggested that early coverage (within 72 hours) yielded more favorable results in terms of better outcomes, a lower rate of infections, and shorter hospital stays.

\section{Type of flap and complications}

In total, 104 cases $(75.36 \%)$ in our study underwent fasciocutaneous flap coverage and 34 cases (24.64\%) underwent musculocutaneous flap coverage. Among the 104 cases of fasciocutaneous flaps, 86 cases (82.7\%) had no complications, while 18 cases (17.3\%) had complications. Among the 34 cases of musculocutaneous flaps, 25 cases (73.5\%) had no complications and nine cases (26.5\%) had complications. Although the difference did not reach statistical significance, musculocutaneous
Table 3. Comparison between acute and chronic cases

\begin{tabular}{|c|c|c|c|c|c|}
\hline Variable & No. & $\begin{array}{c}\text { Acute } \\
(n=39)\end{array}$ & $\begin{array}{c}\text { Chron } \\
(n=99)\end{array}$ & $\begin{array}{c}\text { Chi- } \\
\text { square }\end{array}$ & P-value \\
\hline Age (yr) & & & & 5.103 & 0.403 \\
\hline$\leq 20$ & 17 & $3(7.7)$ & $14(14.1)$ & & \\
\hline $21-30$ & 47 & $13(33.3)$ & 34 (34.3) & & \\
\hline $31-40$ & 28 & $7(17.9)$ & 21 (21.2) & & \\
\hline $41-50$ & 32 & $13(33.3)$ & 19 (19.2) & & \\
\hline $51-60$ & 10 & $3(7.7)$ & $7(7.1)$ & & \\
\hline$>60$ & 4 & 0 & $4(4.0)$ & & \\
\hline Sex & & & & 0.579 & 0.447 \\
\hline Female & 23 & $8(20.5)$ & 15 (15.2) & & \\
\hline Male & 115 & 31 (79.5) & $84(84.8)$ & & \\
\hline Soft tissue defect (cm) & & & & 3.840 & 0.279 \\
\hline$<5$ & 0 & 0 & 0 & & \\
\hline $5-10$ & 15 & $5(12.8)$ & $10(10.1)$ & & \\
\hline $10-15$ & 23 & $10(25.6)$ & $13(13.1)$ & & \\
\hline $15-20$ & 45 & $10(25.6)$ & 35 (35.4) & & \\
\hline$>20$ & 55 & $14(35.9)$ & $41(41.4)$ & & \\
\hline Status of bone & & & & 76.536 & $<0.001^{\text {a) }}$ \\
\hline With periosteum & 44 & $34(87.2)$ & $10(10.1)$ & & \\
\hline Without periosteum & 94 & $5(12.8)$ & 89 (89.9) & & \\
\hline Bony spur & & & & 0.397 & 0.529 \\
\hline Absent & 137 & $39(100)$ & 98 (99.0) & & \\
\hline Present & 1 & 0 & $1(1.0)$ & & \\
\hline Infection & & & & 1.623 & 0.203 \\
\hline Absent & 134 & $39(100)$ & $95(96.0)$ & & \\
\hline Present & 4 & 0 & $4(4.0)$ & & \\
\hline Partial necrosis & & & & 1.208 & 0.272 \\
\hline Absent & 135 & $39(100)$ & $96(97.0)$ & & \\
\hline Present & 3 & 0 & $3(3.0)$ & & \\
\hline Flap necrosis & & & & 3.968 & $0.046^{a)}$ \\
\hline Absent & 119 & 30 (76.9) & 89 (89.9) & & \\
\hline Present & 19 & $9(23.1)$ & 10 (10.1) & & \\
\hline Complications & & & & 6.656 & 0.155 \\
\hline None & 111 & $30(76.9)$ & 81 (81.8) & & \\
\hline Bone spur & 1 & 0 & $1(1.0)$ & & \\
\hline Flap necrosis & 19 & $9(23.1)$ & $10(10.1)$ & & \\
\hline Infection & 4 & 0 & $4(4.0)$ & & \\
\hline Partial necrosis & 3 & 0 & $3(3.0)$ & & \\
\hline Hospital stay (wk) & & & & 6.304 & 0.278 \\
\hline$\leq 1$ & 4 & $1(2.6)$ & $3(3.0)$ & & \\
\hline $1-2$ & 14 & $5(12.8)$ & $9(9.1)$ & & \\
\hline $2-3$ & 20 & $3(7.7)$ & 17 (17.2) & & \\
\hline $3-4$ & 28 & $12(30.8)$ & 16 (16.2) & & \\
\hline $4-5$ & 33 & $10(25.6)$ & 23 (23.2) & & \\
\hline$>6$ & 39 & $8(20.5)$ & 31 (31.3) & & \\
\hline Type of fixation & & & & 0.029 & 0.864 \\
\hline External fixation & 97 & 27 (69.2) & 70 (70.7) & & \\
\hline Internal fixation & 41 & $12(30.8)$ & 29 (29.3) & & \\
\hline
\end{tabular}

Values are presented as number (\%).

a) Statistically significant, $\mathrm{P}<0.05$.

flaps showed a higher percentage of complications (26.5\%). However, in a comparison of complications among the different flap groups, a higher percentage of flap necrosis was seen in perforator flaps (including propeller flaps), accounting for $21.1 \%$ of 
cases. This association was statistically significant $(P=0.001)$. The complications can be attributed to the proximity of these perforators to the zone of trauma with probable microscopic intimal damage that was not identified intraoperatively. In addition, perforator-based flaps are more difficult to perform than axial flaps (fasciocutaneous or musculocutaneous) and a refined microscopic technique is required. The complications of bone spur, infection, and partial flap necrosis did not show statistically significant associations with flap type. In a study conducted by Franken et al. [11], when comparing fasciocutaneous flaps and musculocutaneous flaps, fewer postoperative complications were observed in the patients treated with the latter type of flap ( $47.4 \%$ vs. $21.2 \%$, respectively). However, their study did not find a significant correlation between flap type and complications. Li et al. [12] studied flap outcomes in ankle and foot reconstruction. They divided the foot and ankle into anatomically-based sub-regions and evaluated the risk factors that contributed to flap failure. Free flaps were also included in their study.
Their study found that the choice of flap was correlated with failure. However, Rodriguez-Collazo et al. [13] reported that there was no significant difference in outcomes between free and pedicled flaps.

\section{Site of defect and complications}

In our study, soft tissue defects were found in the proximal third of the leg in 39 cases (Fig. 6), the middle third in 40 cases, and the distal third in 46 cases (Figs. 7-9). In three cases, the middle and distal thirds were involved, and in one case, the proximal and middle thirds were involved. No statistically significant correlation was found between the defect site and complications $(\mathrm{P}=0.900)$. However, the anteromedial distal, anteromedial proximal, and anteromedial middle aspects, which accounted for 55 of the 138 cases, had somewhat more complications than the other sites. This can be partly explained because of the higher frequency of defects at these sites. In a study conducted by Kamath et al. [10], soft tissue defects were predominantly
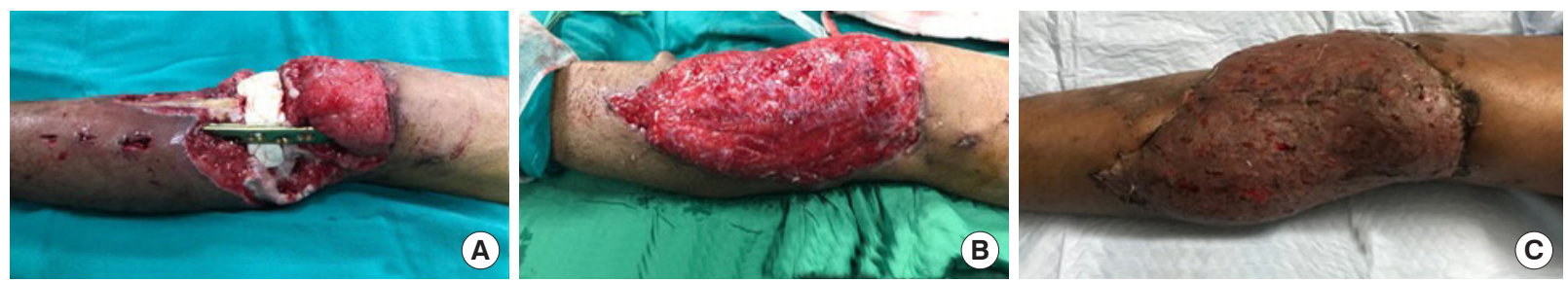

Fig. 6. A gastrocnemius flap for a defect in the proximal leg. (A) Raw surface after internal fixation. (B) Mobilization of the gastrocnemius muscle. (C) Skin grafting over the flap.
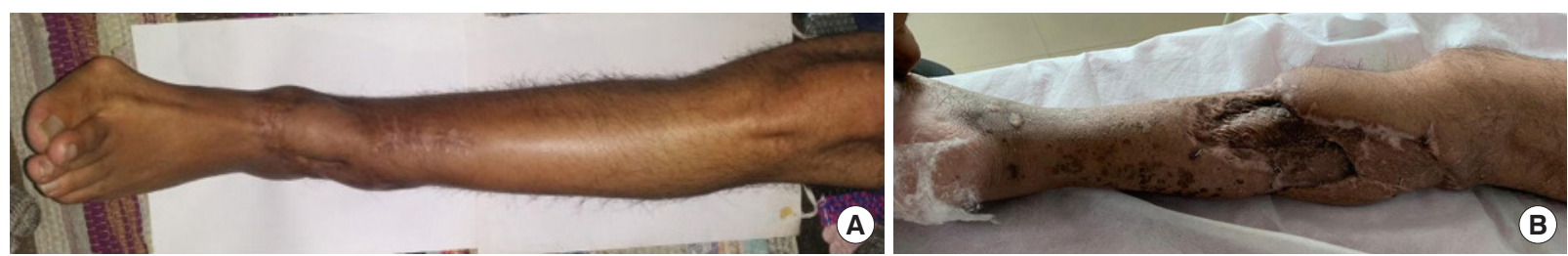

Fig. 7. Clinical photographs of follow-up of island sural flap for distal third of leg (A) and superior based medial fasciocutaneous flap (B).
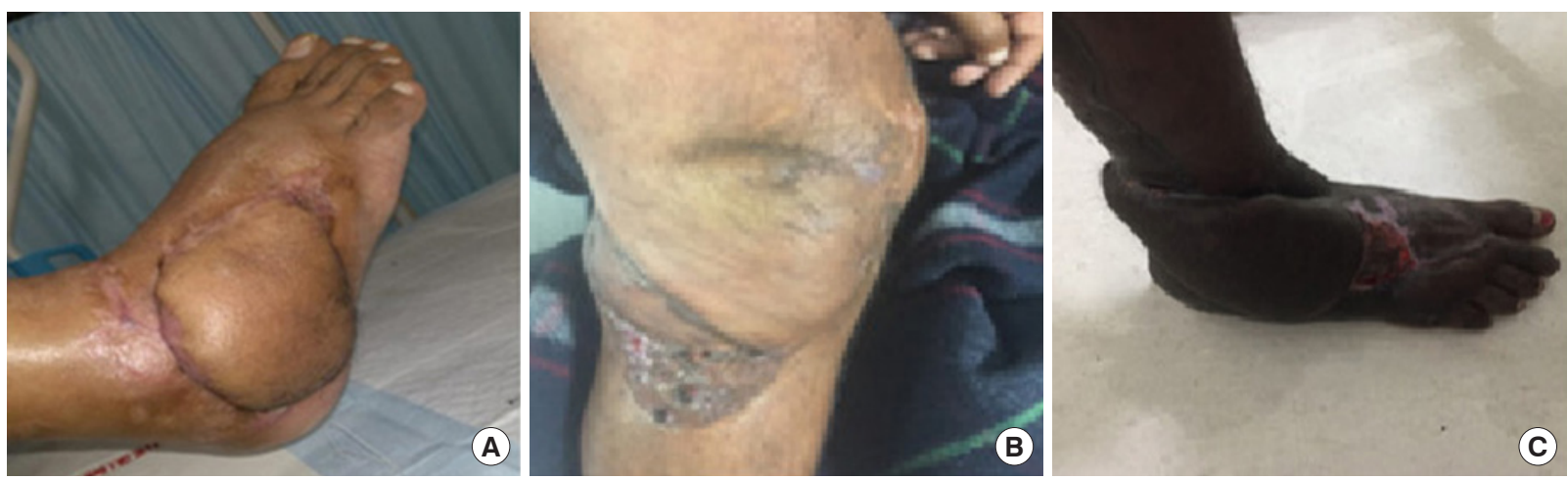

Fig. 8. Clinical photographs of follow-up of inferior-based lateral fasciocutaneous flap (A), superior-based medial fasciocutaneous flap (B), and sural flap for ankle defect (C). 


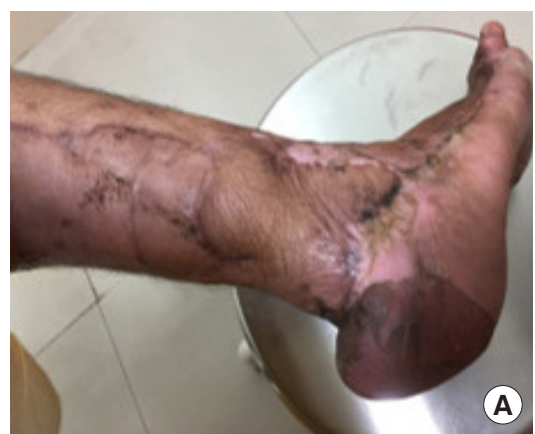

Fig. 9. Clinical photographs of follow-up of sural and inferior-based fasciocutaneous flap. (A) Sural flap for heel defect. (B, C) Follow-up images of inferior-based medial fasciocutaneous flap.
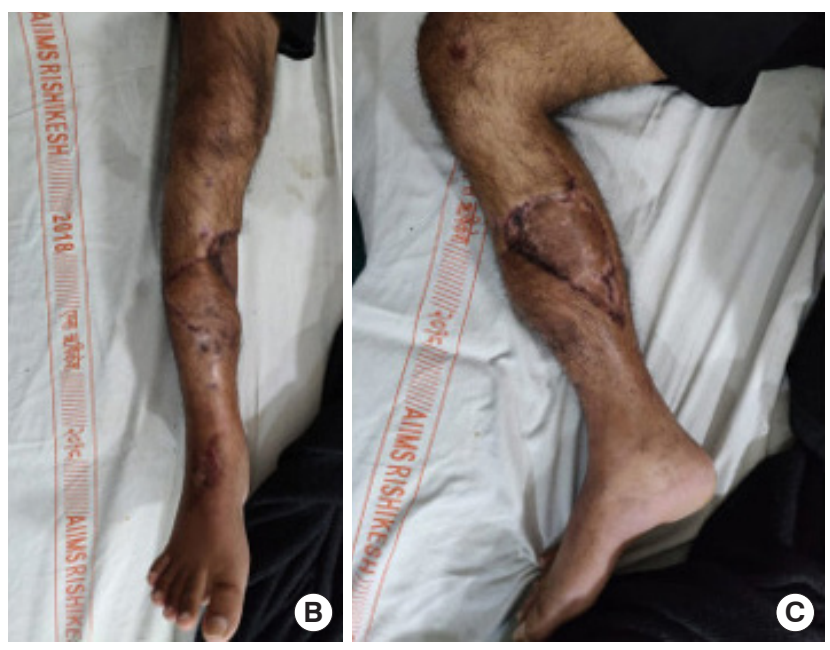

found in the distal third (66 cases), followed by the middle third (45 cases) and the proximal third (33 cases). However, they did not report correlations between the site of soft tissue defects and complications.

\section{Size of defect and complications}

In our study, the cases with defect sizes of 5-10 cm, $10-15 \mathrm{~cm}$, $15-20 \mathrm{~cm}$, and $>20 \mathrm{~cm}$ had complication rates of $26.6 \%, 8.6 \%$, $20 \%$, and $21.8 \%$ respectively, which was not found to be significant $(\mathrm{P}=0.572)$. This finding is in contrast to a study by Shasti et al. [14] on free flaps, which found a significant correlation between large defect size ( $\left.>200 \mathrm{~cm}^{2}\right)$ and partial/total flap failure $(\mathrm{n}=80, \mathrm{P}=0.023)$. In another study by Koepple et al. [15] on 149 patients, wherein for larger defects muscle-based flaps were used $\left(231 \pm 38.6 \mathrm{~cm}^{2}\right)$ and fascio-cutaneous flaps for smaller defects $\left(164 \pm 13.7 \mathrm{~cm}^{2}\right)$, partial flap necrosis was generally more common in muscle- based flaps but no difference was observed in cases of defects larger than $300 \mathrm{~cm}^{2}$.

\section{Type of fixation and complications}

In our study, 97 cases (70.3\%) underwent external fixation and 41 cases (29.7\%) underwent internal fixation. Among the 97 cases of external fixation, 19 cases (19.5\%) had complications, while among the 41 cases of internal fixation eight cases (19.51\%) had complications. However, this did not reflect a statistically significant difference $(\mathrm{P}=0.700)$. In the study of Chua et al. [9], 72 cases (80.89\%) underwent external fixation, 16 cases $(17.97 \%)$ underwent internal fixation, and one case $(1.12 \%)$ received a slab as the initial fixation. In their study, two of 11 flap failure cases (12.5\%) were in intramedullary nailing cases and nine cases (12.5\%) were in cases of external fixation; the difference was not statistically significant. In another study by Kamath et al. [10], 82 of 151 cases (54.30\%) were managed by external fixation and 69 cases $(45.70 \%)$ were managed by in- ternal fixation. They did not report complications with respect to different modalities of fracture fixation.

\section{Other patient factors}

Although our study was limited to the above-discussed factors, a study conducted at the central hospital of Wuhan, China analyzed cases of anterolateral thigh free flap failures and reported that the mental health of the patient was the factor most closely associated with the outcomes of free flap procedures [16]. To further investigate this factor, it would be worthwhile for further research to investigate correlations between a preoperative psychological assessment and flap complications.

\section{Flap factors}

Mishra et al. [17] reported that complications were predominantly observed when latissimus dorsi muscle or musculocutaneous flaps were used to reconstruct small defects, and attributed this tendency to the muscle bulk and kinking of the long pedicle.

\section{Factors contributing to prolongation of the hospital stay} The proportion of cases with a hospital stay lasting for $>3$ weeks progressively increased from $6 \%$ to $18 \%, 34 \%$, and $42 \%$ as the size of soft tissue defect increased from $5-10 \mathrm{~cm}$ to $10-15$ $\mathrm{cm}, 15-20 \mathrm{~cm}$, and $>20 \mathrm{~cm}$, which was a statistically significant relationship $(\mathrm{P}=0.030)$. Pastars et al. [18] reported 153 cases of oral cancer where they removed the tumor and simultaneously placed free flaps on the defect. The average hospital stay was 20.5 days (range, $8-44$ days). They observed that the duration of hospital stay was significantly longer $(\mathrm{P}<0.05)$ when the tumor-and hence the defect made after removal of the tumorwas larger.

Although similar studies have been conducted in the past, a noteworthy contribution of this study is that it investigated the 
relationships of patient-, defect-, and surgeon-related factors with overall complications (including flap necrosis) and hospital stay. Unlike the differential complication rates observed in other studies, such as that by Kamath et al. [10], our study did not find a statistically significant difference between the use of fasciocutaneous flaps and muscle or musculocutaneous flaps. Hence, we are convinced that the choice of flaps to be used in various zones of the leg should depend on further procedures, such as bone exploration or tendon transfers. In cases requiring secondary procedures, it is recommended to use a flap that provides a skin component along with the flap itself (i.e., a fasciocutaneous or musculocutaneous flap) depending on the site of defect.

\section{Major points of this study}

The major points derived from this study are as follows: first, age did not show a significant correlation with complications after flap surgery, but the proportion of complications did increase with age. Second, surgery performed within 3 weeks after trauma was associated with a significantly higher risk of complications in local flaps. Third, no significant difference in the complication rate was found between fasciocutaneous flaps and musculocutaneous flaps. Fourth, flap necrosis was observed significantly more frequently in propeller flaps (a type of perforator flap) than in any other flap. Fifth, the size of the defect was not a significant contributor to complications, but it did have an impact on the length of hospital stay. Sixth, no significant difference was found in the complication rate between internal and external fixation.

\section{Conclusion}

The timing of the surgical intervention (within 3 weeks from the time of injury) and the use of propeller flaps (a type of perforator flap) for reconstruction was associated with a significantly higher rate of complications. Although age and defect size were not associated with the complication rate, the length of hospital stay was significantly affected by the choice of flap. Furthermore, the authors recommend internal fixation for bone stabilization to promote technical ease for reconstruction purposes, as the type of fixation did not alter the complication rate.

\section{NOTES}

\section{Conflict of interest}

No potential conflict of interest relevant to this article was reported.

\section{Ethical approval}

The study was approved by the Institutional Review Board of
All India Institute of Medical Sciences (IRB No. AIIMS/ IEC/21/211) and performed in accordance with the principles of the Declaration of Helsinki. Written informed consent was obtained.

\section{Patient consent}

The patients provided written informed consent for the publication and the use of their images.

\section{Author contribution}

Conceptualization: M Dhingra, D Chattopadhyay. Data curation: M Vathulya, M Dhingra, H Nongdamba, VK Dhingra. Formal analysis: M Dhingra, H Nongdamba, A Kapoor. Methodology: D Chattopadhyay, V Mago, P Kandwal. Project administration: VK Dhingra. Writing - original draft: M Vathulya, M Dhingra. Writing - review \& editing: M Vathulya, M Dhingra, A Kapoor.

\section{ORCID}

Madhubari Vathulya https://orcid.org/0000-0002-7050-5990 Mohit Dhingra https://orcid.org/0000-0001-6798-9173 Hawaibam Nongdamba

https://orcid.org/0000-0003-4348-9312

Debarati Chattopadhyay https://orcid.org/0000-0002-0167-7561

Akshay Kapoor https://orcid.org/0000-0003-4223-9039 Vandana Kumar Dhingra

https://orcid.org/0000-0002-3006-8597

Vishal Mago https://orcid.org/0000-0003-1254-3048

Pankaj Kandwal https://orcid.org/0000-0002-8801-6909

\section{REFERENCES}

1. Chan JK, Harry L, Williams G, et al. Soft-tissue reconstruction of open fractures of the lower limb: muscle versus fasciocutaneous flaps. Plast Reconstr Surg 2012;130:284e-295e.

2. de Blacam C, Colakoglu S, Ogunleye AA, et al. Risk factors associated with complications in lower-extremity reconstruction with the distally based sural flap: a systematic review and pooled analysis. J Plast Reconstr Aesthet Surg 2014;67:60716.

3. Jordan DJ, Malahias M, Hindocha S, et al. Flap decisions and options in soft tissue coverage of the lower limb. Open Orthop J 2014;8:423-32.

4. Kang MJ, Chung CH, Chang YJ, et al. Reconstruction of the lower extremity using free flaps. Arch Plast Surg 2013;40: 575-83.

5. Ivanov PA, Shibaev EU, Nevedrov AV, et al. Emergency soft 
tissue reconstruction algorithm in patients with open tibia fractures. Open Orthop J 2016;10:364-74.

6. Innocenti M, Menichini G, Baldrighi C, et al. Are there risk factors for complications of perforator-based propeller flaps for lower-extremity reconstruction? Clin Orthop Relat Res 2014;472:2276-86.

7. Lese I, Grobbelaar AO, Sabau D, et al. The propeller flap for traumatic distal lower-limb reconstruction: risk factors, pitfalls, and recommendations. J Bone Joint Surg Am 2020; 102:510-8.

8. Huang YQ, Gou R, Diao YS, et al. Charlson comorbidity index helps predict the risk of mortality for patients with type 2 diabetic nephropathy. J Zhejiang Univ Sci B 2014;15:5866.

9. Chua W, De SD, Lin WK, et al. Early versus late flap coverage for open tibial fractures. J Orthop Surg (Hong Kong) 2014;22:294-8.

10. Kamath JB, Shetty MS, Joshua TV, et al. Soft tissue coverage in open fractures of tibia. Indian J Orthop 2012;46:462-9.

11. Franken JM, Hupkens P, Spauwen PH. The treatment of soft-tissue defects of the lower leg after a traumatic open tibial fracture. Eur J Plast Surg 2010;33:129-33.

12. Li X, Cui J, Maharjan S, et al. Reconstruction of the foot and ankle using pedicled or free flaps: perioperative flap survival analysis. PLoS One 2016;11:e0167827.

13. Rodriguez-Collazo E, Khan A, DiPierro D, et al. A systematic review of outcomes and flap selection following lower extremity free tissue transfer versus vascularized perforator pedicle flap transfer in lower limb reconstruction. Int J Orthoplastic Surg 2018; 1:55-66.

14. Shasti M, Jauregui JJ, Malik A, et al. Magnitude of soft-tissue defect as a predictor of free flap failures: does size matter? J Orthop Trauma 2017;31:e412-7.

15. Koepple C, Kallenberger AK, Pollmann L, et al. Comparison of fasciocutaneous and muscle-based free flaps for soft tissue reconstruction of the upper extremity. Plast Reconstr Surg Glob Open 2019; 7:e2543.

16. Yang X, Yan H, Fan Y, et al. Risk factors of free anterolateral thigh flap failure for reconstruction of lower-limb defects: a 10-year experience. Int J Clin Exp Med 2018;11:11028-37.

17. Mishra S, Bhatnagar A, Tyagi R, et al. Limitations and complications of latissimus dorsi flap: a hospital-based study. Saudi J Health Sci 2013;2:31-6.

18. Pastars K, Zarins J, Tars J, et al. Microsurgical reconstruction of oral defects with free flaps for patients with oral cancer: an 8 year experience with 153 consecutive cases. Stomatologija 2018;20:39-42. 